\title{
F-box/WD-40 repeat-containing protein 7: A potential target in the progression and treatment of gastrointestinal malignancy (Review)
}

\author{
YIZHI WANG $^{1}$, YANG $\mathrm{AN}^{2}, \mathrm{YI} \mathrm{MA}^{3}$ and JUNCHAO GUO ${ }^{1}$ \\ ${ }^{1}$ Department of General Surgery, Peking Union Medical College Hospital, \\ Chinese Academy of Medical Sciences and Peking Union Medical College, Beijing 100730; \\ Departments of ${ }^{2}$ Anesthesia and ${ }^{3}$ Thoracic Surgery, First Hospital of China \\ Medical University, Shenyang, Liaoning 110001, P.R. China
}

Received August 24, 2018; Accepted January 21, 2019

DOI: $10.3892 / 01.2019 .10036$

\begin{abstract}
Cancer is a principal cause of human morbidity and mortality, with gastrointestinal malignancies, in particular, resulting in a marked number of tumor-associated mortalities. The progression of gastrointestinal malignancy is regulated by a variety of aberrantly expressed proteins, a number of which facilitate tumor progression, whereas, others function as tumor suppressors. The detection of such proteins not only contributes to the early diagnosis of cancer, they may additionally serve as potential therapeutic targets. In normal tissues, numerous proteins encoded by proto-oncoproteins are degraded by ubiquitylation enzymes, consisting of F-box/WD-40 repeat-containing protein 7 (Fbw7) and other proteins, thus avoiding tumorigenesis and maintaining homeostasis. In tumor tissues, the downregulation of Fbw7, caused by various factors, leads to disorders in ubiquitinase synthesis, which may induce tumor progression and chemoresistance, particularly in gastrointestinal malignancy. Therefore, an in-depth study of the regulatory mechanisms involved in disorders of Fbw7 expression and the role of Fbw7 in chemoresistance of gastrointestinal tumors may suggest improvements for early diagnostic screening and targeted therapy.
\end{abstract}

\section{Contents}

1. Introduction

2. Structure and biological functions of Fbw7

3. Regulatory mechanisms of Fbw7 in tumorigenesis

Correspondence to: Dr Junchao Guo, Department of General Surgery, Peking Union Medical College Hospital, Chinese Academy of Medical Sciences and Peking Union Medical College, 1 Shuaifuyuan Road, Dongcheng, Beijing 100730, P.R. China E-mail: gjcpumch@163.com

Key words: F-box and WD-40 repeat-containing protein 7, gastrointestinal malignancy, targeted therapy, tumor progression, chemoresistance
4. Role of Fbw7 in chemoresistance

5. Fbw7 and gastrointestinal malignancy

6. Fbw7 and other types of cancer

7. Conclusions and future prospects

\section{Introduction}

Cancer remains a principal cause of human mortalities worldwide. The incidence of cancer and the consequent mortalities are a principal cause for concern. It is estimated that by 2030 , there may be 22 million novel cases of cancer and 13 million mortalities worldwide each year due to different types of cancer (1). In China, the incidence of cancer has increased between 215.8 cases per 100,000 people in 2003 and 250.3 cases per 100,000 people in 2011 (2). The onset of gastrointestinal malignancy is frequently clinically silent (3), with the early occurrence of tumor invasion and metastasis leading to high mortality rates (4). For example, at present, the 5-year survival rate for pancreatic cancer is $8 \%$, whereas, the 5 -year survival rate for patients with distant metastases is 3\% (5). Due to early vessel metastasis of pancreatic cancer, it may be difficult to conduct radical surgical resections for advanced gastrointestinal malignancies in certain situations (6). Therefore, effective targeted therapy may be indispensable in reducing the severity of gastrointestinal malignancies and the degree of radical surgery required.

F-box/WD-40 repeat-containing protein 7 (Fbw7) is a member of the F-box protein family. Fbw7 is an essential component of the E3 ubiquitin ligase, S-phase kinase-associated protein 1 (Skp1)-cullin-1 (Cul1)-F-box $(\mathrm{SCF})^{\mathrm{Fbw} 7}$, which serves as a binding site for substrates, and mediates their ubiquitination and degradation (7). The majority of Fbw7 substrates regulate a number of cell behaviors, including progression through the cell cycle, differentiation and apoptosis (7). In solid tumors, Fbw7 substrates are typically identified to be oncoproteins. Therefore, $F B W 7$, which encodes Fbw7, is frequently considered a tumor suppressor gene (7). In tumor cells, $F B W 7$ has been demonstrated to possess mutations and deletions, to be methylated or post-transcriptionally modified (8). Fbw7 expression is additionally regulated by numerous proteins, resulting in its dysfunctional expression 
and subsequent tumor progression (8). The present review aimed to provide a comprehensive overview of the mechanisms involved in dysfunctional Fbw7 expression caused by mutations in the $F B W 7$ gene. Additionally, it may provide information on the shared molecular regulatory mechanisms involved in the progression of gastrointestinal malignancies, including colorectal, liver, gastric and pancreatic cancer, in addition to oral and esophageal squamous cell carcinomas.

\section{Structure and biological functions of Fbw7}

Fbw7 (additionally termed Fbxw7, hAgo, hCdc4 and SEL-10) is a protein encoded by the $F B W 7$ gene and is located on the chromosomal band 4q32 (9). Fbw7 is present as one of three subtypes: Fbw $7 \alpha$ exists in the nucleoplasm; Fbw7 $\beta$ exists in the cytoplasm; and Fbw7 $\gamma$ exists in the nucleoli (9). Each of the three subtypes are transcribed by a different promoter, and thus, are considered as three different proteins (9). At present, the regulatory mechanisms of the three proteins remain largely unknown. Of the three subtypes, Fbw7 $\alpha$ serves a leading ubiquitylation role (9). All of the three isoforms contain a dimerization-domain that mediates protein dimerization and regulates substrate binding and ubiquitination, an F-box connecting Skp1 and a WD40 repeat region that forms a $\beta$ propeller, binding to phosphorylated substrates (9). Fbw7 binds to Skp1, Cul1 and E3 ubiquitin-protein ligase RBX1 to form an SCF E3 ubiquitin ligase, which allows the ubiquitination of substrates, together with E1 ubiquitin-activating and E2 ubiquitin-conjugating enzymes (Fig. 1). The cell division control protein 4 phosphorylation domain (CPD) of substrates is recognized by Fbw7 and leads to their ubiquitylation subsequent to being phosphorylated by glycogen synthase kinase 3 (GSK3). The majority of substrates that are recognized for degradation by Fbw7 contain at least one CPD (10). Numerous substrates of Fbw7, including Myc proto-oncogene protein (c-Myc), Neurogenic locus notch homolog protein (Notch), cyclin E and c-Jun, are vital due to their important regulatory role in tumor progression; Fbw7 serves as a scavenger by degrading such substrates (9). Additionally, previous studies demonstrated that substrates of Fbw7, including myeloid cell leukemia 1, mediator complex subunit 13/13 ligand, Krüppel-like factor 5, thymine guanine-interacting factor and numerous other proteins, may additionally exert their influence on tumor progression (Fig. 2) (11-14).

\section{Regulatory mechanisms of Fbw7 in tumorigenesis}

In normal tissues, Fbw7 is stably expressed, maintaining a balance between tumor suppressor proteins and proto-oncoproteins in vivo, thus inhibiting tumor progression (15). In tumor tissues, FBW7 is typically mutated, resulting in the downregulation or dysfunction of Fbw7 (15). During transcription, multiple transcriptional factors bind to Fbw7 mRNA to decrease the expression level of Fbw7, including a number of miRNAs $(16,17)$ and p53 (18). Proteins may bind to the functional region of Fbw7, resulting in an incomplete or non-functional E3 ubiquitin ligase and other proteins may promote the self-ubiquitination of Fbw7, targeting itself for degradation, including the role of Parkin (19). Upregulation of proteins that result in the downregulation, dysfunction or degradation of Fbw7 expression serve key roles in tumorigenesis (Fig. 3).

Missense point mutations on three arginine residues (R465, R479 and R505) occurring at the $\beta$ propeller phosphorylation-binding site, impair the substrate recognition function of Fbw7 (9). Additionally, monoallelic or biallelic knockouts or the hypermethylation of the promoter of $F B W 7$ may occur in tumors, in humans and in mice (20-22). Numerous previous studies demonstrated that microRNAs (miRs), including miR-223 and miR-27a, bind to Fbw7 mRNA in tumors, leading to the inhibition of Fbw7 expression $(23,24)$. Dimerization and post-transcriptional modifications stabilize the structure of Fbw7. Specifically, dimerization of Fbw7 improves its affinity for substrates, whereas, post-transcriptional modifications allow Fbw7 to alter between an autocatalytic mode and a substrate degradation mode (7). A mutation of the CPD at the binding site of Fbw7 decreases the affinity of Fbw7 for a substrate, resulting in downstream substrate accumulation (25). In addition to mutations of $F B W 7$ and modifications of product structure subsequent to transcription and translation, the expression of Fbw7 is regulated by a variety of other factors. Ubiquitin specific peptidase (Usp) 28 regulates the stability of Fbw7 and the degradation of substrates through a series of complex mechanisms (26). Loss of the deubiquitinase Usp28 monoallele stabilizes and facilitates Fbw7-mediated substrate degradation, whereas, complete knockout of Usp28 promotes the degradation of Fbw7, leading to the accumulation of Fbw7 substrates (26). Cellular tumor antigen p53 (p53) directly binds to the first exon of $F B W 7$ and promotes Fbw7 expression. Therefore, targeted activation of the p53 signaling pathway exerts antitumor effects by restoring Fbw7 expression (18). In addition, Peptidyl-prolyl cis-trans isomerase NIMA-interacting 1 (Pin1), CCAAT/enhancer-binding protein- $\delta(C / E B P-\delta)$, hairy and enhancer of split (Hes)-5 and Numb additionally regulate the expression of Fbw7 (17). Of the aforementioned proteins, C/EBP- $\delta$ and Hes- 5 are additionally substrates of Fbw7 $(13,27)$.

\section{Role of Fbw7 in chemoresistance}

Fbw7 serves a crucial role in chemoresistance. Chemotherapy is an effective adjuvant therapy to radical surgery. However, the chemoresistance that cancer cells develop to various chemotherapy drugs is one of the principal obstacles of successfully treating cancer. The mutation in $F B W 7$, including $F B W 7$ missense mutation in three arginine residues (R465, R479 and R505), which leads to dysfunctional Fbw7, can cause the accumulation of numerous substrates, which may be important in chemoresistance (28). Gong et al (29) conducted a comprehensive review of the role of F-box proteins in chemoresistance, including Fbw7. Numerous previous studies investigated the involvement of $\mathrm{Fbw} 7$ in the chemoresistance of numerous types of cancer (11,30-32). A number of downstream targets of Fbw7, including c-Myc, nuclear factor erythroid 2-related factor 2, myeloid leukemia cell differentiation protein Mcl-1 (Mcl-1) and transcription factor SOX-9, are involved in chemoresistance of various types of cancer, including colorectal cancer, gastric cancer and pancreatic cancer (11,30-32). In comparison, a number of upstream proteins, including Epstein-Barr virus nuclear 


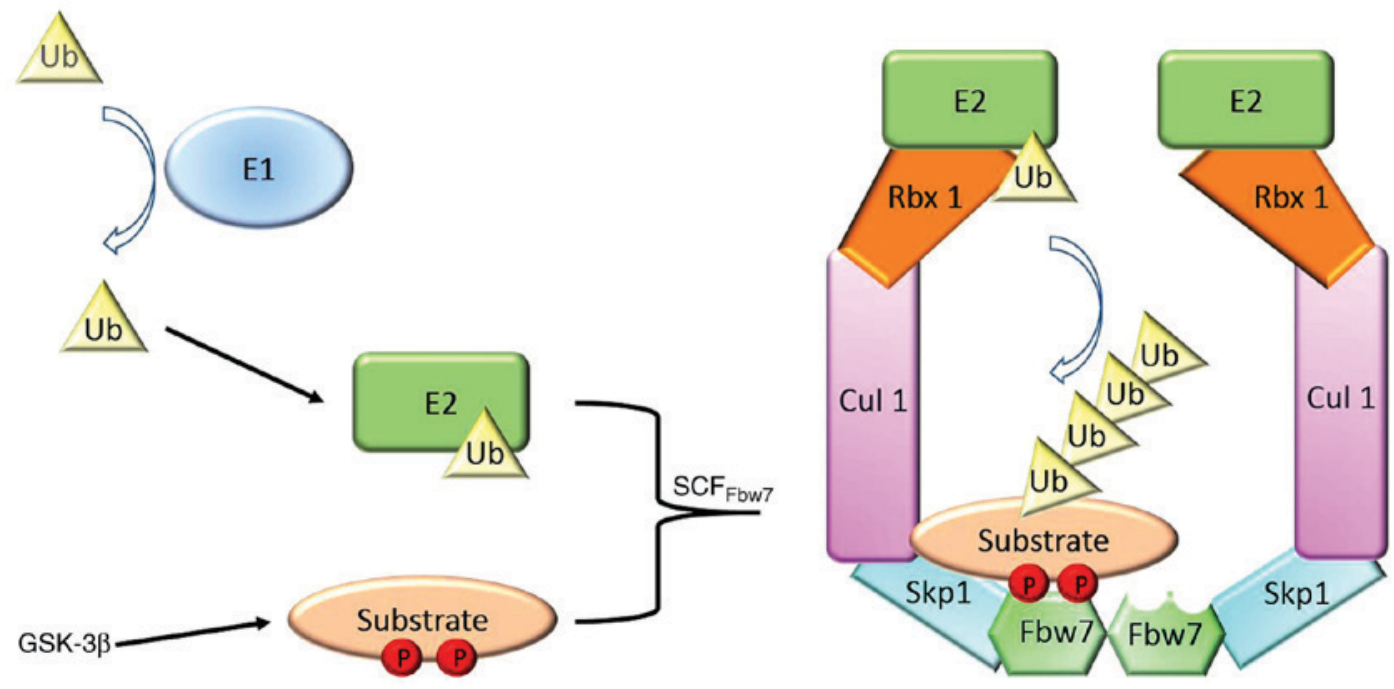

Figure 1. A total of two cell division control protein 4 phosphorylation domains of the substrates are phosphorylated by GSK-3 $\beta$ and bind to Fbw7 in the

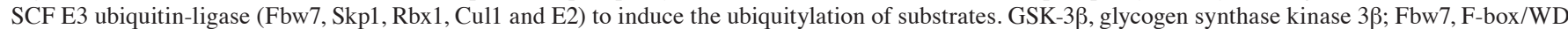
repeat-containing protein 7; SCF, Skp1-Cul-F-box; Rbx1, ring box protein-1; E1, E1 ubiquitin-activating enzyme; E2, E2 ubiquitin-conjugating enzyme; Ub, ubiquitin; Skp1, S-phase kinase-associated protein 1; Cul1, cullin-1; p, phosphate.

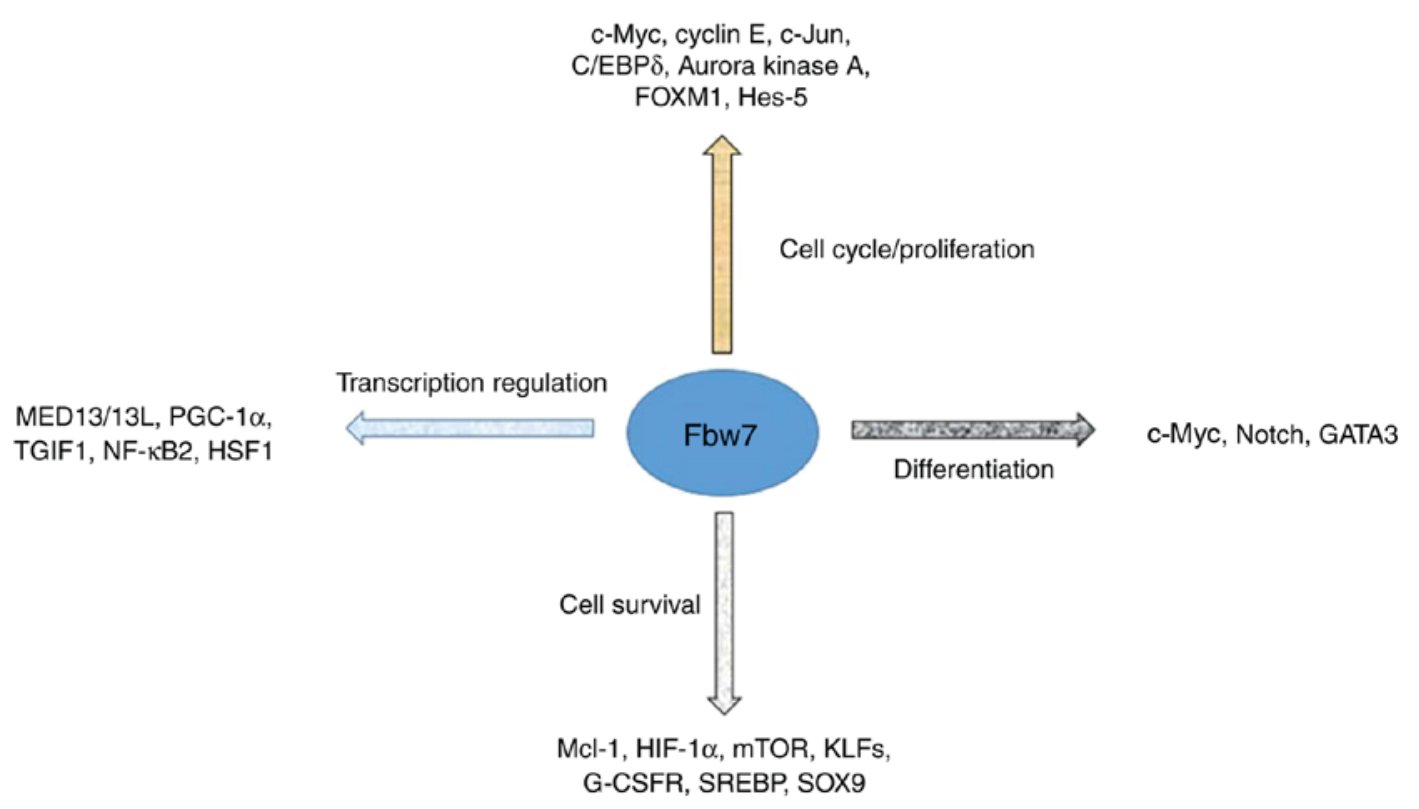

Figure 2. Important substrates for downstream regulation of Fbw7 in tumors. Fbw7 F-box/WD repeat-containing protein 7; c-Myc, Myc proto-oncogene protein; C/EBPS, CCAAT/enhancer binding protein $\delta$; FOXM1, forkhead box protein M1; Hes-5, hairy and enhancer of split 5; Notch, neurogenic locus notch homolog protein; GATA3, trans-acting T-cell-specific transcription factor; HIF-1 $\alpha$, hypoxia-inducible factor-1 $\alpha$; mTOR, mammalian target of rapamycin; KLFs, Krueppel-like factors; G-CSFR, granulocyte colony-stimulating factor receptor; SREBP, sterol regulatory element-binding protein; SOX9, transcription factor SOX-9; MED13/13L, mediator complex subunit 13/13 ligand; PGC-1 $\alpha$, peroxisome proliferator-activated receptor gamma coactivator-1 $\alpha$; TGIF1, thymine-guanine interacting factor; NF- $\mathrm{B} 2$, nuclear factor $\kappa$-light-chain-enhancer of activated B cells 2; HSF1, heat shock factor protein 1; Mcl-1, induced myeloid leukemia cell differentiation protein Mcl-1.

antigen-binding protein 2 (33), C/EBP- $\delta$ (13) and miR-27a (34), may regulate $F B W 7$ to increase drug sensitivity. Therefore, the downregulation of such proteins may lead to chemoresistance, and increasing the expression of these proteins may be a novel method for overcoming chemoresistance. Additionally, the miR-223/Fbw7 signaling pathway has been demonstrated to serve an important role in chemoresistance of numerous gastrointestinal malignancies, including oral and esophageal squamous (35), gastric (36), pancreatic (37) cancer. Therefore, targeting the miR-223/Fbw7 pathway may be an effective way to overcome chemoresistance in gastrointestinal cancer.

\section{Fbw7 and gastrointestinal malignancy}

Fbw7 is able to promote ubiquitination and degrade a number of key proteins that regulate the cell cycle, proliferation and apoptosis and thus, serves as a tumor suppressor. In mitosis, the deletion of Fbw7 causes hyperphosphorylation of a serine residue at position 18 of the centromere 


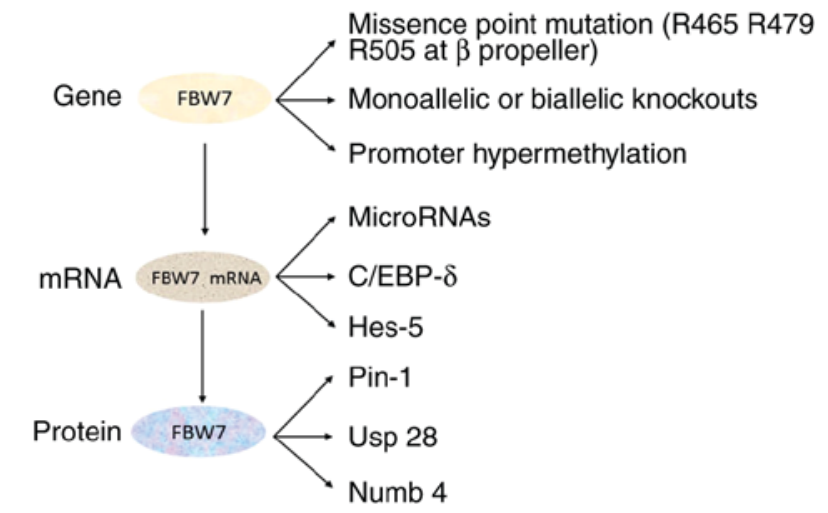

Figure 3. Regulatory mechanisms and associated proteins that cause Fbw7 dysfunction at different expression levels. Fbw7, F-box/WD repeat-containing protein 7 ; $\mathrm{C} / \mathrm{EBP} \delta, \mathrm{CCAAT} / \mathrm{enhancer}$ binding protein $\delta$; Hes-5, hairy and enhancer of split 5; Pin-1, peptidyl-prolyl cis-trans isomerase NIMA-interacting 1; USP28, ubiquitin specific peptidase 28.

recognition protein, histone $\mathrm{H} 3$-like centromeric protein-A, by cyclin E1/cyclin-dependent kinase 2 (CDK2) resulting in the inability of the centromere to become localized, in addition to increased chromosomal instability and the promotion of tumorigenesis (38). Fbw7 additionally mediates $\gamma$-catenin ubiquitination, resulting in an inhibition of the $\mathrm{G} 2 / \mathrm{M}$ cell cycle transition and cell proliferation (39). Furthermore, Fbw7 is closely associated with epithelial to mesenchymal transition (EMT), invasion and metastasis (40). Numerous previous studies investigated the association between $F B W 7$ mutations and clinicopathological features of gastrointestinal malignancies (Table I). A number of the previous studies in Table I suggested that a poor prognosis was closely associated with $F B W 7$ mutations. In a number of previous studies, it was demonstrated that aberrant Fbw7 expression additionally serves a pivotal role in the resistance of numerous gastrointestinal tumors to chemotherapeutic drugs (Table II). Therefore, examining novel methods to restore the physiological expression levels of Fbw 7 may increase the sensitivity of tumors to chemotherapy and thus facilitate the treatment of cancer.

Colorectal cancer. Next-generation sequencing of 648 colorectal cancer specimens demonstrated that the mutational rates of $F B W 7$ in the Chinese population was $5.32 \%$ (41). Disorders in Fbw7 expression caused by $F B W 7$ mutation, including mutation in $\mathrm{Arg}^{465}$ significantly increased the depth of invasion of colorectal cancer and shortened the 5-year overall survival rate of patients (41). The accumulation of cyclin E and c-Myc caused by dysfunctional Fbw7 expression increases the malignancy of colorectal cancer (42). A recent study demonstrated that Fbw7 restricted the metastasis of colorectal cancer cells by inhibiting the hypoxia-inducible factor- $\alpha$ (HIF- $\alpha$ )/carcino-embryonic antigen cell adhesion molecule 5 (CEACAM5) axis, which lead to a loss of CEACAM5, the gene encoding a common tumor marker, CEA (43). Polo-like kinase 2 expression was increased in colorectal cancer tissues, and directly bound to and phosphorylated Fbw7 on serine 176, forming a complex that reduced the stability of Fbw7 and lead to retention of cyclin E, which was beneficial to the proliferation of tumors $(44,45)$. Zinc finger protein 746 additionally inhibited c-Myc phosphorylation by GSK3 and decreased the degradation of c-Myc by Fbw7 (46). Furthermore, the sequential upregulation of miR-182 and miR-503, may transform colorectal adenomas into colorectal cancer by inhibiting Fbw7 expression (47). In contrast, the deubiquitinase, ubiquitin specific peptidase 9, X-linked, inhibited Fbw7 self-ubiquitination and proteolysis, stabilized and restored Fbw7 function, and suppressed the progression of colorectal cancer (48). The sensitivity of colorectal cancer to chemotherapeutics is, to a certain extent, associated with the expression of Fbw7. Downregulation of Fbw7 resulted in the accumulation of cryptochrome 2 , which increased the resistance of colorectal cancer to oxaliplatin (49). Additionally, an increase in the Fbw7 substrate Mcl-1, mediated resistance of colorectal cancer to regorafenib (28).

Hepatocellular carcinoma. A previous Japanese study, which examined liver cancer tissue samples from 66 cases and followed up the survival rates of the patients, demonstrated that tumor-free survival of patients with high Fbw7 expression was considerably longer compared with patients with low Fbw7 expression (50). Multivariate analysis identified that the decreased expression of Fbw7 was the strongest independent risk factor for the recurrence of hepatocellular carcinoma (50). The positive correlation between Fbw7 and the survival rate of patients with liver cancer may be associated with the downregulation of Notch-1 and the expression of downstream matrix metalloproteinase (MMP)-2, MMP-9 and urokinase plasminogen activator, which obstruct the invasion and metastasis of liver cancer (51). Expression of Fbw7 in liver cancer is additionally regulated by a wide-range of proteins. Signal transduction and activator of transcription (STAT)-1 expression downregulates the expression level of Fbw7 and p53, increases the expression of downstream cyclin E, CDK2, Hes-1 and nuclear factor $-\kappa \mathrm{B}(\mathrm{NF}-\kappa \mathrm{B})$ transcription factor p65, accelerates cell growth and promotes G0/G1 cell cycle transition and apoptosis (52). Long non-coding RNA cancer susceptibility candidate 2 can bind and sequester miR-367, restoring Fbw7 expression (53). Fbw7 is associated with chemoresistance of liver cancer. Hepatocellular carcinoma cell lines with increased expression of Fbw7 were more sensitive to doxorubicin and demonstrated decreased EMT (54). In addition, the increase in expression of Mcl-1 by the Pin1-mediated downregulation of Fbw7 expression may enhance the resistance of liver cancer to sorafenib (55).

Gastric cancer. To date, four missense mutations, a frame shift mutation and a nonsense mutation of $F B W 7$ have been identified in gastric cancer tissues; and an $F B W 7$ mutation has been identified in early gastric cancer (56). An $F B W 7$ monoallele deletion increased the carcinogenic risk of healthy cells to methylnitrosourea (57). A recent Chinese study demonstrated that dysfunctional Fbw 7 expression caused by $F B W 7$ mutations were associated with poor tissue differentiation, survival and adjuvant chemotherapy resistance (58). $F B W 7$ mutations were additionally associated with lymph node metastasis, tumor size and p53 mutations in gastric cancer, leading to a poor prognosis (59). The tumorigenic effects of $F B W 7$ mutations are manifested as a result of its interactions with numerous substrates. Therefore, screening for $F B W 7$ mutations may 
Table I. FBW7 mutations, dysfunction and clinicopathological features of gastrointestinal malignancy.

\begin{tabular}{|c|c|c|c|c|}
\hline Author, year & Type of cancer & $\begin{array}{l}\text { Number of } \\
\text { specimens }\end{array}$ & Conclusion & (Refs.) \\
\hline Iwatsuki et al, 2010 & Colorectal cancer & 223 & $\begin{array}{l}\text { Low Fbw7 expression enhances tumor invasion } \\
\text { and results in a significant poor prognosis. }\end{array}$ & $(42)$ \\
\hline Chang et al, 2015 & Colorectal cancer & 1,519 & $\begin{array}{l}\text { There is no significant association between } \\
\text { patient prognosis and } F B W 7 \text { mutation. }\end{array}$ & $(87)$ \\
\hline Tu et al, 2012 & $\begin{array}{l}\text { Hepatocellular } \\
\text { carcinoma }\end{array}$ & 60 & $\begin{array}{l}\text { Fbw } 7 \text { protein expression is significantly } \\
\text { associated with high histological grade } \\
\text { and advanced Tumor Node Metastasis stage. }\end{array}$ & $(88)$ \\
\hline Enkhbold et al, 2014 & $\begin{array}{l}\text { Intrahepatic cholangioc } \\
\text { arcinoma }\end{array}$ & 31 & $\begin{array}{l}\text { Tumor progression is associated with with low Fbw } 7 \\
\text { expression, and low Fbw } 7 \text { expression is an } \\
\text { independent prognosis factor for overall } \\
\text { survival and mortality free survival. }\end{array}$ & (89) \\
\hline Ishii et al, 2017 & Pancreatic cancer & 122 & $\begin{array}{l}\text { Decreased Fbw } 7 \text { expression facilitates advanced } \\
\text { venous invasion, enhanced Ki-67 expression } \\
\text { and poor prognosis. }\end{array}$ & $(90)$ \\
\hline Imura et al, 2014 & $\begin{array}{l}\text { Hepatocellular } \\
\text { carcinoma }\end{array}$ & 66 & $\begin{array}{l}\text { The tumor-free survival of patients with high } \\
\text { Fbw } 7 \text { expression is considerably longer } \\
\text { compared with patients with low expression. }\end{array}$ & $(50)$ \\
\hline Li et al, 2017 & Gastric cancer & 570 & $\begin{array}{l}\text { Low Fbw } 7 \text { expression correlated with poor } \\
\text { differentiation and prognosis and worse } \\
\text { chemotherapy response. }\end{array}$ & $(58)$ \\
\hline Yokobori et al, 2009 & Gastric cancer & 100 & $\begin{array}{l}\text { FBW7 mutations may additionally increase } \\
\text { lymph node metastasis and tumor size, } \\
\text { and lead to a poor prognosis. }\end{array}$ & $(59)$ \\
\hline Naganawa et al, 2010 & Esophageal cancer & 43 & $\begin{array}{l}\text { FBW7 deficiency results in a poor prognosis and } \\
\text { promote tumor cell proliferation, myometrial } \\
\text { invasion and lymphatic metastasis. }\end{array}$ & (63) \\
\hline Arita et al, 2017 & Oral cancer & 125 & $\begin{array}{l}\text { Low expression of Fbw } 7 \text { was poorly correlated with } \\
\text { preoperative chemotherapy and the poor prognosis. }\end{array}$ & (66) \\
\hline
\end{tabular}

Fbw7, F-box/WD repeat-containing protein 7; Ki-67, proliferation marker protein Ki-67.

improve the diagnosis and detection of early gastric cancer. As a substrate of Fbw7, transforming protein RhoA interacts with downstream effectors to damage the cytoskeleton, restrict cell migration, disrupt the cell cycle of tumors, and is closely associated with tumorigenesis and tumor invasion (60). The expression of Fbw7 in gastric cancer was inhibited by miR-223, which promoted tumor apoptosis and proliferation. A previous in-depth study demonstrated that the upregulation of miR-223 additionally increased the resistance of gastric cancer cells to cisplatin by downregulating the expression of Fbw7 and thus affecting G1/S cell cycle transition (35). In receptor tyrosine-protein kinase erbB-2 positive gastric cancer cell lines, the miR-223/Fbw7 axis is a pivotal pathway for mediating trastuzumab resistance $(61,62)$.

Oral and esophageal squamous cell carcinoma. A deficiency in the $F B W 7$ gene copy number may lead to the decreased expression of Fbw7 and an increase in c-Myc expression levels, resulting in poor a prognosis in patients with esophageal cancer. It may additionally promote tumor cell proliferation, myometrial invasion and lymphatic metastases $(63,64)$. A previous next-generation sequencing study of oral squamous cell carcinoma specimens from a Taiwanese population demonstrated that $F B W 7$ is one of the most commonly mutated genes $(2 \%)$ (62). Furthermore, compared with a high expression level of Fbw7, low expression of Fbw7 correlated with a poor prognosis following pre-operative chemotherapy. In addition, Fbw7 expression has become an independent predictor of oral squamous cell carcinoma (65). Therefore, Fbw7, in addition to serving as a potential biomarker for an oral squamous cell carcinoma response to chemotherapeutic drugs, may additionally allow for improved prediction of the overall survival of patients (66).

A number of miRs regulate the expression of $\mathrm{Fbw} 7$ in oral and esophageal cancer. miR-223 serves a role in the progression of gastric cancer and esophageal cancer. Additionally, miR-223 was upregulated and inhibited the expression of Fbw7, resulting in a poor prognosis (34). Furthermore, 
Table II. Mechanisms of Fbw7 in the chemoresistance of a number of gastrointestinal malignancies.

\begin{tabular}{|c|c|c|c|c|}
\hline Author, year & Type of cancer & Chemotherapeutics & Mechanism & (Refs.) \\
\hline Fang et al, 2015 & Colorectal cancer & $\begin{array}{l}\text { Oxaliplatin-based } \\
\text { neoadjuvant } \\
\text { chemotherapy }\end{array}$ & $\begin{array}{l}\text { Loss of Fbw7 upregulates } \\
\text { the expression level of } \\
\text { CRY2, which mediates } \\
\text { chemoresistance }\end{array}$ & (49) \\
\hline Tong et al, 2017 & Colorectal cancer & $\begin{array}{l}\text { Regorafenib } \\
\text { and sorafenib }\end{array}$ & $\begin{array}{l}\text { Lower Fbw } 7 \text { expression } \\
\text { blocks the degradation } \\
\text { of Mcl-1. }\end{array}$ & (28) \\
\hline Yu et al, 2014 & $\begin{array}{l}\text { Hepatocellular } \\
\text { carcinoma }\end{array}$ & Doxorubicin & $\begin{array}{l}\text { Silencing of Fbw } 7 \text { in } \\
\text { heptocarcinoma } \\
\text { facilitates chemoresistance } \\
\text { by regulating EMT. }\end{array}$ & (54) \\
\hline Zhou et al, 2015 & Gastric cancer & Cisplatin & $\begin{array}{l}\text { The miR-223/Fbw } 7 \text { axis may } \\
\text { alter some certain cell cycle } \\
\text { regulators. }\end{array}$ & (61) \\
\hline Eto et al, 2015 & Gastric cancer & Trastuzumab & $\begin{array}{l}\text { The miR-223/Fbw } 7 \text { axis } \\
\text { induces chemoresistance } \\
\text { by suppressing cell apoptosis. }\end{array}$ & $(62)$ \\
\hline Ma et al, 2015 & Pancreatic cancer & Gemcitabine & $\begin{array}{l}\text { The miR-223/Fbw } 7 \text { axis } \\
\text { induces chemoresistance } \\
\text { by regulating EMT and } \\
\text { upregulating Notch-1. }\end{array}$ & $(40)$ \\
\hline
\end{tabular}

EMT, epithelial-to-mesenchymal transition; miR, microRNA; Fbw7, F-box/WD repeat-containing protein 7; Mcl-1, induced myeloid leukemia cell differentiation protein Mcl-1; Notch-1, neurogenic locus notch homolog protein-1; CRY2, cryptochrome-2.

miR-25 was involved in the poor prognosis of patients with esophageal cancer, by promoting invasion and metastasis of esophageal cancer by downregulating the expression of Fbw7 (67). Although previous studies identified an intrinsic association between $F B W 7$ mutations and the pathological features, and prognosis of oral and esophageal squamous cell carcinomas (65-68), There are a limited number of studies, to the best of our knowledge, on the regulatory mechanisms of upstream and downstream molecules.

Pancreatic cancer. A previous study on pancreatic cancer cell lines overexpressing cyclin E demonstrated that a number of the cell lines possessed an $F B W 7$ allele loss, which promoted the progression of pancreatic cancer (68). Fbw7 may inhibit cancer by degrading numerous oncoproteins in pancreatic cancer. The expression of exportin-1 (Xpo1) facilitates the transport of Fbw7, which prevents the degradation of Notch-1 in the nucleus, leading to the accumulation of c-Myc, cyclin D, Hes-1 and vascular endothelial growth factor in the Notch signaling pathway (69). The Xpo1-specific inhibitor, KPT-185, and Xpo1 inhibition by an inhibitor of nuclear export interferes with this process (69). Fbw7 additionally degrades $\beta$-catenin to block an abnormally regulated Wnt signaling pathway in pancreatic cancer (70). In the diagnosis of pancreatic cancer, the Fbw7 expression level in pancreatic cancer was inversely correlated with the maximum standardized uptake value in positron emission tomography and coaxial tomography, and inhibited glucose metabolism via an Fbw7/c-Myc/thioredoxin-interacting protein axis (71). Additionally, Fbw7 expedited the accumulation of equilibrative nucleoside transporter 1 by inhibiting the degradation function of lysosomes, and enhanced the sensitivity of pancreatic cancer to gemcitabine (72). The function of Fbw7 is additionally regulated by a variety of mechanisms in pancreatic cancer. A KRAS proto-oncogene, GTPase mutation activated extracellular signal-regulated kinase (ERK) to directly bind to a threonine at position 205 of Fbw7, resulting in ERK degradation. However, a lack of threonine at this site in Fbw7 resulted in ERK dysfunction and lead to an inability of Fbw7 degradation (73). Genistein inhibits cell growth, invasion and metastasis, and induces apoptosis due to the increased expression of miR-223 and decreased expression of Fbw7, promoting EMT to enhance pancreatic cancer resistance to gemcitabine $(36,39)$. Notably, Fbw7 degrades the GSK3 phosphorylated miR-223 agonist, heterogenous nuclear ribonucleoprotein $\mathrm{K}$, resulting in miR-223 dysfunction (74).

\section{Fbw7 and other types of cancer}

Additionally, Fbw7 is involved in the progression of other tumors. In a previous study by Yu et al (54), transfection of Fbw7 into a non-small cell lung cancer cell line, NCI-H1299, which exhibits low endogenous expression levels of Fbw7, 
significantly increased its chemosensitivity to cisplatin, which was closely associated with the effect of Fbw7 on EMT. Therefore, Fbw7 may be regarded as a potential target for lung cancer resistance (75). An additional previous study on drug resistance in non-small cell lung cancer demonstrated that ERK, combined with GSK3 $\beta$, phosphorylated the serine 159 residue of $\mathrm{Mcl}-1$, which promoted the degradation of Mcl-1 in the nucleus by binding to Fbw7. In tumor tissues, the lack of Fbw7 disrupted this process and induced drug resistance in non-small cell lung cancer (76). Lin et al (77) demonstrated that Fbw7 overexpression inhibited proliferation, invasion and metastasis of the glioma cell lines, U251 and U373, by downregulating Aurora B, Mcl-1 and Notch-1 expression levels, and enhanced the cytotoxicity of temozolomide. Fbw7 additionally serves a role in the development of triple-negative breast cancer. Takada et al (78) demonstrated that EgIN2 prolyl hydroxylase promoted tumorigenesis in breast cancer and was regulated by Fbw7. Following phosphorylation of GSK $3 \beta$ at the C-terminus of EgIN2, the latter became ubiquitylated and degraded by Fbw7 (78). In addition, Fbw7 overexpression significantly decreased the viability of the activated B cell-like diffuse large B lymphoma cell lines, SU-DHL-2 and OCI-LY-3, and increased their apoptotic rate (79). This process is caused by Fbw7 ubiquitination and degradation of STAT3 and phosphorylated STAT3 ${ }^{\text {Tyr705}}$, resulting in the dysfunction of downstream anti-apoptotic proteins, Myc, survivin, Mcl-1, serine/threonine-protein kinase pim-1, B-cell lymphoma-2 (Bcl-2) and Bcl2-associated agonist of cell death (79).

\section{Conclusions and future prospects}

Dysfunctional Fbw7 is closely associated with the progression, invasion, metastasis and chemoresistance of tumors as a result of deficiencies in the ubiquitylation and degradation of substrates that serve as oncoproteins in tumor progression. In gastrointestinal tumors, the Fbw 7 expression level is typically aberrantly downregulated, and the detailed mechanisms involved are diverse. At the genetic level, $F B W 7$ mutations may lead to increased dysfunctional expression. At the transcriptional level, miRs bind to Fbw7 mRNA, thus the proteins are not translated. At the post-transcriptional level, the stability of Fbw7 is regulated by numerous various upstream regulatory proteins, whereas, physiological ubiquitination function is abrogated by deubiquitinases. In addition, mutations in the CPD region of substrates result in a loss of affinity to Fbw7, resulting in dysfunctional ubiquitination by Fbw7. The frequent presence of mutations in $F B W 7$ in tumors may constitute $F B W 7$ as an early tumor screening gene. Fbw 7 may additionally be used as an essential protein target for targeted therapy to reverse chemoresistance. Approaches against Fbw7 in anti-tumor therapy may include knocking out $F B W 7$ variant genes, targeting upstream proteins of Fbw7 and substrates of Fbw7 that have cancer-promoting effects, and exogenously upregulating the expression of Fbw7 to reverse tumorigenesis.

Bromodomain containing protein-7 (BRD7), is a subunit of switch/sucrose non-fermenting (SWI/SNF), which is an evolutionarily conserved, large ( 2 MDa) multi-subunit, ATP-dependent chromatin remodeling complex that regulates epigenetic architecture and cellular identity (80). Similar to Fbw7, mutations of BRD7 may lead to SWI/SNF dysfunction, which causes aberrant gene expression leading to various diseases, including prostate cancer, breast cancer and nasopharyngeal cancer (80-82). The mechanisms include regulating the cell cycle, serving as a co-activator of p53, c-Myc, HIF- $\alpha$ and $\mathrm{NF}-\kappa \mathrm{B}$, and downregulating the expression of BRD7 in cancer (83). Therefore, it was hypothesized that Fbw7 and BRD7 may be tumor suppressors, and they may be synergistic in tumor inhibition. However, the specific association between Fbw7 and BRD7 remains unknown, and requires further study.

Compared with other gastrointestinal malignancies, the survival rate for pancreatic cancer is decreased, suggesting the urgency in identifying specific targets to reduce the degree of radical surgery undertaken. Although a variety of adjuvant and neoadjuvant chemotherapeutic agents exist, the overall survival rate of pancreatic cancer has remained unaltered over the past few decades. Therefore, studies on Fbw7 may provide novel insight for targeted therapy for advanced pancreatic cancer. However, studies of the role of Fbw7 in pancreatic cancer have only gradually emerged in recent years $(71,72,84)$. A previous study demonstrated that $\mathrm{Fbw} 7$ regulates the expression of $\mathrm{NF}-\kappa \mathrm{B}$ and vice versa (85). $\mathrm{NF}-\kappa \mathrm{B}$ is closely correlated with angiogenesis, invasion and metastasis of pancreatic cancer (86). However, limited studies exist on the association between Fbw7 and $\mathrm{NF}-\kappa \mathrm{B}$ in pancreatic cancer. Therefore, the regulation of Fbw7 and the $\mathrm{NF}-\kappa \mathrm{B}$ signaling pathway may become the focus of future studies in targeted therapy for pancreatic cancer.

In conclusion, the present review discusses the mechanisms of Fbw7 in the progression of gastrointestinal malignancies. Fbw7, in addition to upstream and downstream regulatory proteins, were suggested to be potential tumor therapeutic targets. Previous studies provided insight for the regulatory mechanisms of Fbw 7 in gastrointestinal malignancies. However, specific issues require investigation. Upstream and downstream signaling molecules and signaling pathways that specifically affect Fbw7 expression have not yet been examined. Additionally, the diagnostic specificity and sensitivity of $F B W 7$ as a biomarker for cancer and the veracity of prognosis prediction requires further improvement. Furthermore, large-scale clinical and multicenter trials as opposed to cell culture or animal studies require gradual implementation to examine chemotherapeutics targeting Fbw7.

\section{Acknowledgements}

Not applicable.

\section{Funding}

The present study was supported by The China Academy of Medical Sciences Innovation Fund for Medical Sciences (grant no. 2016-I2M-3-019) and the non-profit Central Research Institute Fund of Chinese of Academy of Medical Sciences (grant no. 2018PT32014).

\section{Availability of data and materials}

Not applicable. 


\section{Authors' contributions}

In this review, study concept and design was conducted by YW and JG. YW and YA drafted the manuscript. Analysis of data was performed by YA and YM. Critical revision of the manuscript for important intellectual content was conducted by YW, YA and JG. All authors agreed the final version.

\section{Ethics approval and consent to participate}

Not applicable.

\section{Patient consent for publication}

Not applicable.

\section{Competing interests}

The authors declare that they have no competing interests.

\section{References}

1. Ferlay J, Soerjomataram I, Dikshit R, Eser S, Mathers C, Rebelo M, Parkin DM, Forman D and Bray F: Cancer incidence and mortality worldwide: Sources, methods and major patterns in GLOBOCAN 2012. Int J Cancer 136: E359-E386, 2015.

2. Tsoi KK, Hirai HW, Chan FC, Griffiths S and Sung JJ: Cancer burden with ageing population in urban regions in China: Projection on cancer registry data from World Health Organization. Br Med Bull 121: 83-94, 2017.

3. Lieberman D, Ladabaum U, Cruz-Correa M, Ginsburg C, Inadomi JM, Kim LS, Giardiello FM and Wender RC: Screening for colorectal cancer and evolving issues for physicians and patients: A review. JAMA 316: 2135-2145, 2016.

4. Arkan MC: Cancer: Fat and the fate of pancreatic tumours. Nature 536: 157-158, 2016.

5. Siegel RL, Miller KD and Jemal A: Cancer statistics. CA Cancer J Clin 68: 7-30, 2018.

6. Li S, Xu HX, Wu CT, Wang WQ, Jin W, Gao HL, Li H, Zhang SR, $\mathrm{Xu} \mathrm{JZ}$, Qi ZH, et al: Angiogenesis in pancreatic cancer: Current research status and clinical implications. Angiogenesis: Aug 24, 2018 (Epub ahead of print).

7. Xu W, Taranets L and Popov N: Regulating Fbw7 on the road to cancer. Semin Cancer Biol 36: 62-70, 2016.

8. Cao J, Ge MH and Ling ZQ: Fbxw7 tumor suppressor: A vital regulator contributes to human tumorigenesis. Medicine (Baltimore) 95: e2496, 2016.

9. Davis RJ, Welcker M and Clurman BE: Tumor suppression by the Fbw7 ubiquitin ligase: Mechanisms and opportunities. Cancer Cell 26: 455-464, 2014.

10. Shimizu K, Nihira NT, Inuzuka H and Wei W: Physiological functions of FBW7 in cancer and metabolism. Cell Signal 46: $15-22,2018$.

11. Inuzuka H, Shaik S, Onoyama I, Gao D, Tseng A, Maser RS, Zhai B, Wan L, Gutierrez A, Lau AW, et al: SCF(FBW7) regulates cellular apoptosis by targeting MCL1 for ubiquitylation and destruction. Nature 471: 104-109, 2011.

12. Davis MA, Larimore EA, Fissel BM, Swanger J, Taatjes DJ and Clurman BE: The SCF-Fbw7 ubiquitin ligase degrades MED13 and MED13L and regulates CDK8 module association with Mediator. Genes Dev 27: 151-156, 2013.

13. Balamurugan K, Sharan S, Klarmann KD, Zhang Y, Coppola V, Summers GH, Roger T, Morrison DK, Keller JR and Sterneck E: FBXW7 $\alpha$ attenuates inflammatory signalling by downregulating C/EBPd and its target gene Tlr4. Nat Commun 4: 1662, 2013.

14. Bengoechea-Alonso MT and Ericsson J: Tumor suppressor Fbxw7 regulates TGF $\beta$ signaling by targeting TGIF1 for degradation. Oncogene 29: 5322-5328, 2010.

15. Hao B, Oehlmann S, Sowa ME, Harper JW and Pavletich NP: Structure of a Fbw7-Skp1-cyclin E complex: Multisite-phosphorylated substrate recognition by SCF ubiquitin ligases. Mol Cell 26: 131-143, 2007.
16. Olive V, Sabio E, Bennett MJ, De Jong CS, Biton A, McGann JC, Greaney SK, Sodir NM, Zhou AY, Balakrishnan A, et al: A component of the mir-17-92 polycistronic oncomir promotes oncogene-dependent apoptosis. Elife 2: e00822, 2013

17. Wang L, Ye X, Liu Y, Wei W and Wang Z: Aberrant regulation of FBW7 in cancer. Oncotarget 5: 2000-2015, 2014.

18. Kimura T, Gotoh M, Nakamura Y and Arakawa H: hCDC4b, a regulator of cyclin $\mathrm{E}$, as a direct transcriptional target of p53. Cancer Sci 94: 431-436, 2003.

19. Ekholm-Reed S, Goldberg MS, Schlossmacher MG and Reed SI: Parkin-dependent degradation of the F-box protein Fbw7b promotes neuronal survival in response to oxidative stress by stabilizing Mcl-1. Mol Cell Biol 33: 3627-3643, 2013.

20. Cerami E, Gao J, Dogrusoz U, Gross BE, Sumer SO, Aksoy BA, Jacobsen A, Byrne CJ, Heuer ML, Larsson E, et al: The cBio cancer genomics portal: An open platform for exploring multidimensional cancer genomics data. Cancer Discov 2: 401-404, 2012.

21. Akhoondi S, Lindström L, Widschwendter M, Corcoran M, Bergh J, Spruck C, Grandér D and Sangfelt O: Inactivation of FBXW7/hCDC4- $\beta$ expression by promoter hypermethylation is associated with favorable prognosis in primary breast cancer. Breast Cancer Res 12: R105, 2010.

22. Wang Z, Inuzuka H, Zhong J, Wan L, Fukushima H, Sarkar FH and Wei W: Tumor suppressor functions of FBW7 in cancer development and progression. FEBS Lett 586: 1409-1418, 2012.

23. Xu Y, Sengupta T, Kukreja L and Minella AC: MicroRNA-223 regulates cyclin $\mathrm{E}$ activity by modulating expression of F-box and WD-40 domain protein 7. J Biol Chem 285: 34439-34446, 2010.

24. Feng DD, Zhang H, Zhang P, Zheng YS, Zhang XJ, Han BW, Luo XQ, Xu L,Zhou H, Qu LH, et al: Down-regulated miR-331-5p and $\mathrm{miR}-27 \mathrm{a}$ are associated with chemotherapy resistance and relapse in leukemia. J Cell Mol Med 15: 2164-2175, 2010.

25. Cheng X, Hao Y, Shu W, Zhao M, Zhao C, Wu Y, Peng X, Yao P, Xiao D, Qing G, et al: Cell cycle-dependent degradation of the methyltransferase SETD3 attenuates cell proliferation and liver tumorigenesis. J Biol Chem 292: 9022-9033, 2017.

26. Schülein-Völk C, Wolf E, Zhu J, Xu W, Taranets L, Hellmann A, Jänicke LA, Diefenbacher ME, Behrens A, Eilers M, et al: Dual regulation of Fbw7 function and oncogenic transformation by Usp28. Cell Rep 9: 1099-1109, 2014.

27. Sancho R, Blake SM, Tendeng C, Clurman BE, Lewis J and Behrens A: Fbw7 repression by hes 5 creates a feedback loop that modulates Notch-mediated intestinal and neural stem cell fate decisions. PLoS Biol 11: e1001586, 2013.

28. Tong J, Tan S, Zou F, Yu J and Zhang L: FBW7 mutations mediate resistance of colorectal cancer to targeted therapies by blocking Mcl-1 degradation. Oncogene 36: 787-796, 2017.

29. Gong J, Zhou Y, Liu D and Huo J: F-box proteins involved in cancer-associated drug resistance. Oncol Lett 15: 8891-8900, 2018.

30. Suryo Rahmanto A, Swartling FJ and Sangfelt O: Targeting SOX9 for degradation to inhibit chemoresistance, metastatic spread, and recurrence. Mol Cell Oncol 4: e1252871, 2016.

31. Yada M, Hatakeyama S, Kamura T, Nishiyama M, Tsunematsu R, Imaki H, Ishida N, Okumura F, Nakayama K and Nakayama KI: Phosphorylation-dependent degradation of c-Myc is mediated by the F-box protein Fbw7. EMBO J 23: 2116-2125, 2004.

32. Biswas M, Phan D, Watanabe M and Chan JY: The Fbw7 tumor suppressor regulates nuclear factor E2-related factor 1 transcription factor turnover through proteasome-mediated proteolysis. J Biol Chem 286: 39282-39289, 2011.

33. Welcker M, Larimore EA, Frappier L and Clurman BE: Nucleolar targeting of the fbw7 ubiquitin ligase by a pseudosubstrate and glycogen synthase kinase 3. Mol Cell Biol 31: 1214-1224, 2011.

34. Lerner M, Lundgren J, Akhoondi S, Jahn A, Ng HF, Akbari Moqadam F, Oude Vrielink JA, Agami R, Den Boer ML, Grandér D and Sangfelt O: MiRNA-27a controls FBW7/hCDC4-dependent cyclin E degradation and cell cycle progression. Cell Cycle 10: 2172-2183, 2011.

35. Kurashige J, Watanabe M, Iwatsuki M, Kinoshita K, Saito S, Hiyoshi Y, Kamohara H, Baba Y, Mimori K and Baba H: Overexpression of microRNA-223 regulates the ubiquitin ligase FBXW7 in oesophageal squamous cell carcinoma. $\mathrm{Br}$ J Cancer 106: 182-188, 2012

36. Li J, Guo Y, Liang X, Sun M, Wang G, De W and Wu W: MicroRNA-223 functions as an oncogene in human gastric cancer by targeting $\mathrm{FBXW} 7 / \mathrm{hCdc} 4$. J Cancer Res Clin Oncol 138: 763-774, 2012 
37. Ma J, Cheng L, Liu H, Zhang J, Shi Y, Zeng F, Miele L, Sarkar FH, Xia J and Wang Z: Genistein down-regulates miR-223 expression in pancreatic cancer cells. Curr Drug Targets 14: 1150-1156, 2013.

38. Takada M, Zhang W, Suzuki A, Kuroda TS, Yu Z Inuzuka $\mathrm{H}$, Gao D, Wan L, Zhuang M, Hu L, et al: FBW7 loss promotes chromosomal instability and tumorigenesis via Cyclin E1/CDK2-mediated phosphorylation of CENP-A. Cancer Res 77: 4881-4893, 2017

39. Li Y, Hu K, Xiao X, Wu W, Yan H, Chen H, Chen Z and Yin D: FBW7 suppresses cell proliferation and G2/M cell cycle transition via promoting $\gamma$-catenin K63-linked ubiquitylation. Biochem Biophys Res Commun 497: 473-479, 2018.

40. Ma J, Fang B, Zeng F, Ma C, Pang H, Cheng L, Shi Y, Wang H, Yin B, Xia J and Wang Z: Down-regulation of miR-223 reverses epithelial-mesenchymal transition in gemcitabine-resistant pancreatic cancer cells. Oncotarget 6: 1740-1749, 2015.

41. Wang Y, Liu H, Hou Y, Zhou X, Liang L, Zhang Z, Shi H, Xu S, Hu P,Zheng Z, et al: Performance validation of an amplicon-based targeted next-generation sequencing assay and mutation profiling of 648 Chinese colorectal cancer patients. Virchows Arch 472: 959-968, 2018

42. Iwatsuki M, Mimori K, Ishii H, Yokobori T, Takatsuno Y, Sato T, Toh H, Onoyama I, Nakayama KI, Baba H and Mori M: Loss of FBXW7, a cell cycle regulating gene, in colorectal cancer: Clinical significance. Int J Cancer 126: 1828-1837, 2010.

43. Li Q, Li Y, Li J, Ma Y, Dai W, Mo S, Xu Y, Li X and Cai S: FBW7 suppresses metastasis of colorectal cancer by inhibiting HIF1 $\alpha / C E A C A M 5$ functional axis. Int J Biol Sci 14: 726-735, 2018

44. Ou B, Zhao J, Guan S, Wangpu X, Zhu C, Zong Y, Ma J, Sun J, Zheng M, Feng $\mathrm{H}$ and Lu A: Plk2 promotes tumor growth and inhibits apoptosis by targeting Fbxw7/Cyclin E in colorectal cancer. Cancer Lett 380: 457-466, 2016.

45. Cizmecioglu O, Krause A, Bahtz R, Ehret L, Malek N and Hoffmann I: Plk2 regulates centriole duplication through phosphorylation-mediated degradation of Fbxw7 (human Cdc4). J Cell Sci 125: 981-992, 2012.

46. Jung JH, Jung DB, Kim H, Lee H, Kang SE, Srivastava SK, Yun M and Kim SH: Zinc finger protein 746 promotes colorectal cancer progression via c-Myc stability mediated by glycogen synthase kinase $3 \beta$ and F-box and WD repeat domain-containing 7. Oncogene 37: 3715-3728, 2018.

47. Li L, Sarver AL, Khatri R, Hajeri PB, Kamenev I, French AJ, Thibodeau SN, Steer CJ and Subramanian S: Sequential expression of miR-182 and miR-503 cooperatively targets FBXW7, contributing to the malignant transformation of colon adenoma to adenocarcinoma. J Pathol 234: 488-501, 2014

48. Khan OM, Carvalho J, Spencer-Dene B, Mitter R, Frith D, Snijders AP, Wood SA and Behrens A: The deubiquitinase USP9X regulates FBW7 stability and suppresses colorectal cancer. J Clin Invest 128: 1326-1337, 2018.

49. Fang L, Yang Z, Zhou J, Tung JY, Hsiao CD, Wang L, Deng Y, Wang P, Wang J and Lee MH: Circadian clock gene CRY2 degradation is involved in chemoresistance of colorectal cancer. Mol Cancer Ther 14: 1476-1487, 2015.

50. Imura S, Tovuu LO, Utsunomiya T, Morine $Y$, Ikemoto $T$, Arakawa Y, Kanamoto M, Iwahashi S, Saito Y, Takasu C, et al: The role of Fbxw7 expression in hepatocellular carcinoma and adjacent non-tumor liver tissue. J Gastroenterol Hepatol 29: $1822-1829,2014$

51. Wang X, Zhang J, Zhou L, Sun W, Zheng ZG, Lu P, Gao Y, Yang XS, Zhang ZC, Tao KS and Dou KF: Fbxw7 regulates hepatocellular carcinoma migration and invasion via Notch1 signaling pathway. Int J Oncol 47: 231-243, 2015.

52. Chen J, Wang H, Wang J, Huang S and Zhang W: STAT1 inhibits human hepatocellular carcinoma cell growth through induction of p53 and Fbxw7. Cancer Cell Int 15: 111, 2015.

53. Wang Y, Liu Z, Yao B, Li Q, Wang L, Wang C, Dou C, Xu M, Liu Q and Tu K: Long non-coding RNA CASC2 suppresses epithelial-mesenchymal transition of hepatocellular carcinoma cells through CASC2/miR-367/FBXW7 axis. Mol Cancer 16 : 123, 2017.

54. Yu J, Zhang W, Gao F, Liu YX, Chen ZY, Cheng LY, Xie SF and Zheng SS: FBW7 increases chemosensitivity in hepatocellular carcinoma cells through suppression of epithelial-mesenchymal transition. Hepatobiliary Pancreat Dis Int 13: 184-191, 2014.

55. Zheng M, Xu H, Liao XH, Chen CP, Zhang AL, Lu W, Wang L, Yang D, Wang J, Liu H, et al: Inhibition of the prolyl isomerase Pinl enhances the ability of sorafenib to induce cell death and inhibit tumor growth in hepatocellular carcinoma. Oncotarget 8: 29771-29784, 2017.
56. Lee JW, Soung YH, Kim HJ, Park WS, Nam SW, Kim SH, Lee JY, Yoo NJ and Lee SH: Mutational analysis of the hCDC4 gene in gastric carcinomas. Eur J Cancer 42: 2369-2373, 2006

57. Jiang Y, Qi X, Liu X, Zhang J, Ji J, Zhu Z, Ren J and Yu Y: Fbxw7 haploinsufficiency loses its protection against DNA damage and accelerates MNU-induced gastric carcinogenesis. Oncotarget 8 : 33444-33456, 2017.

58. Li MR, Zhu CC, Ling TL, Zhang YQ, Xu J, Zhao EH and Zhao G: FBXW7 expression is associated with prognosis and chemotherapeutic outcome in Chinese patients with gastric adenocarcinoma. BMC Gastroenterol 17: 60, 2017.

59. Yokobori T, Mimori K, Iwatsuki M, Ishii H, Onoyama I, Fukagawa T, Kuwano H, Nakayama KI and Mori M: p53-Altered FBXW7 expression determines poor prognosis in gastric cancer cases. Cancer Res 69: 3788-3794, 2009

60. Li H, Wang Z, Zhang W, Qian K, Xu W and Zhang S: Fbxw7 regulates tumor apoptosis, growth arrest and the epithelial-to-mesenchymal transition in part through the RhoA signaling pathway in gastric cancer. Cancer Lett 370: 39-55, 2016.

61. Zhou X, Jin W, Jia H, Yan J and Zhang G: MiR-223 promotes the cisplatin resistance of human gastric cancer cells via regulating cell cycle by targeting FBXW7. J Exp Clin Cancer Res 34: 28 , 2015.

62. Eto K, Iwatsuki M, Watanabe M, Ishimoto T, Ida S, Imamura Y, Iwagami S, Baba Y, Sakamoto Y, Miyamoto Y, et al: The sensitivity of gastric cancer to trastuzumab is regulated by the miR-223/FBXW7 pathway. Int J Cancer 136: 1537-1545, 2015.

63. Naganawa Y, Ishiguro H, Kuwabara Y, Kimura M, Mitsui A, Katada T, Tanaka T, Shiozaki M, Fujii Y and Takeyama H: Decreased expression of FBXW7 is correlated with poor prognosis in patients with esophageal squamous cell carcinoma. Exp Ther Med 1: 841-846, 2010.

64. Yokobori T, Mimori K, Iwatsuki M, Ishii H, Tanaka F, Sato T, Toh H, Sudo T, Iwaya T, Tanaka Y, et al: Copy number loss of FBXW7 is related to gene expression and poor prognosis in esophageal squamous cell carcinoma. Int J Oncol 41: 253-259, 2012.

65. Er TK, Wang YY, Chen CC, Herreros-Villanueva M, Liu TC and Yuan SS: Molecular characterization of oral squamous cell carcinoma using targeted next-generation sequencing. Oral Dis 21: 872-878, 2015

66. Arita H, Nagata M, Yoshida R, Matsuoka Y, Hirosue A, Kawahara K, Sakata J, Nakashima H, Kojima T, Toya R, et al: FBXW7 expression affects the response to chemoradiotherapy and overall survival among patients with oral squamous cell carcinoma: A single-center retrospective study. Tumour Biol: Oct 26, 2017 (Epub ahead of print). doi: 1010428317731771, 2017.

67. Hua Y, Zhao K, Tao G, Dai C and Su Y: miR-25 promotes metastasis via targeting FBXW7 in esophageal squamous cell carcinoma. Oncol Rep 38: 3030-3038, 2017.

68. Calhoun ES, Jones JB, Ashfaq R, Adsay V, Baker SJ, Valentine V, Hempen PM, Hilgers W, Yeo CJ, Hruban RH and Kern SE: BRAF and FBXW7 (CDC4, FBW7, AGO, SEL10) mutations in distinct subsets of pancreatic cancer: Potential therapeutic targets. Am J Pathol 163: 1255-1260, 2003

69. Gao J, Azmi AS, Aboukameel A, Kauffman M, Shacham S, Abou-Samra AB and Mohammad RM: Nuclear retention of Fbw7 by specific inhibitors of nuclear export leads to Notch 1 degradation in pancreatic cancer. Oncotarget 5: 3444-3454, 2014.

70. Jiang JX, Sun CY, Tian S, Yu C, Chen MY and Zhang H: Tumor suppressor Fbxw7 antagonizes WNT signaling by targeting $\beta$-catenin for degradation in pancreatic cancer. Tumour Biol 37: 13893-13902, 2016

71. Ji S, Qin Y, Liang C, Huang R, Shi S, Liu J, Jin K, Liang D, Xu W, Zhang B, et al: FBW7 (F-box and WD Repeat Domain-Containing 7) negatively regulates glucose metabolism by targeting the c-Myc/TXNIP (Thioredoxin-Binding Protein) axis in pancreatic cancer. Clin Cancer Res 22: 3950-3960, 2016.

72. Hu Q, Qin Y, Zhang B, Liang C, Ji S, Shi S, Xu W, Xiang J, Liang D, Ni Q, et al: FBW7 increases the chemosensitivity of pancreatic cancer cells to gemcitabine through upregulation of ENT1. Oncol Rep 38: 2069-2077, 2017.

73. Ji S, Qin Y, Shi S, Liu X, Hu H, Zhou H, Gao J, Zhang B, Xu W, Liu J, et al: ERK kinase phosphorylates and destabilizes the tumor suppressor FBW7 in pancreatic cancer. Cell Res 25: 561-573, 2015.

74. He D, Huang C, Zhou Q, Liu D, Xiong L, Xiang H, Ma G and Zhang Z: HnRNPK/miR-223/FBXW7 feedback cascade promotes pancreatic cancer cell growth and invasion. Oncotarget 8: 20165-20178, 2017. 
75. Yu HG, Wei W, Xia LH, Han WL, Zhao P, Wu SJ, Li WD and Chen W: FBW7 upregulation enhances cisplatin cytotoxicity in non-small cell lung cancer cells. Asian Pac J Cancer Prev 14: 6321-6326, 2013

76. Ye M, Zhang Y, Zhang X, Zhang J, Jing P, Cao L, Li N, Li X, Yao L, Zhang J and Zhang J: Targeting FBW7 as a strategy to overcome resistance to targeted therapy in non-small cell lung cancer. Cancer Res 77: 3527-3539, 2017

77. Lin J, Ji A, Qiu G, Feng H, Li J, Li S, Zou Y, Cui Y, Song C, He H and Lu Y: FBW7 is associated with prognosis, inhibits malignancies and enhances temozolomide sensitivity in glioblastoma cells. Cancer Sci 109: 1001-1011, 2018

78. Takada M, Zhuang M, Inuzuka H, Zhang J, Zurlo G, Zhang J and Zhang Q: EglN2 contributes to triple negative breast tumorigenesis by functioning as a substrate for the FBW7 tumor suppressor. Oncotarget 8: 6787-6795, 2017.

79. Yao S, Xu F, Chen Y, Ge Y, Zhang F, Huang H, Li L, Lin D, Luo $\mathrm{X}, \mathrm{Xu} \mathrm{J}$, et al: Fbw7 regulates apoptosis in activated B-cell like diffuse large B-cell lymphoma by targeting Stat3 for ubiquitylation and degradation. J Exp Clin Cancer Res 36: 10, 2017.

80. Liang Y, Dong B, Shen J, Ma C and Ma Z: Clinical significance of bromodomain-containing protein 7 and its association with tumor progression in prostate cancer. Oncol Lett 17: 849-856, 2019.

81. Niu W, Luo Y, Wang X, Zhou Y, Li H, Wang H, Fu Y, Liu S Yin S, Li J, et al: BRD7 inhibits the Warburg effect and tumor progression through inactivation of HIF1 $\alpha /$ LDHA axis in breast cancer. Cell Death Dis 9: 519, 2018.

82. Liu Y, Zhao R, Wei Y, Li M, Wang H, Niu W, Zhou Y, Qiu Y, Fan S, Zhan Y, et al: BRD7 expression and c-Myc activation forms a double-negative feedback loop that controls the cell proliferation and tumor growth of nasopharyngeal carcinoma by targeting oncogenic miR-141. J Exp Clin Cancer Res 37: 64, 2018.

83. Yu X, Li Z and Shen J: BRD7: A novel tumor suppressor gene in different cancers. Am J Transl Res 8: 742-748, 2016.

84. Jin X, Yang C, Fan P, Xiao J, Zhang W, Zhan S, Liu T, Wang D and Wu H: CDK5/FBW7-dependent ubiquitination and degradation of EZH2 inhibits pancreatic cancer cell migration and invasion. J Biol Chem 292: 6269-6280, 2017.
85. Arabi A, Ullah K, Branca RM, Johansson J, Bandarra D, Haneklaus M, Fu J, Ariës I, Nilsson P, Den Boer ML, et al: Proteomic screen reveals Fbw7 as a modulator of the NF- $\mathrm{KB}$ pathway. Nat Commun 3: 976, 2012.

86. Zeligs KP, Neuman MK and Annunziata CM: Molecular pathways: The balance between cancer and the immune system challenges the therapeutic specificity of targeting nuclear Factor- $\mathrm{KB}$ signaling for cancer treatment. Clin Cancer Res 22: 4302-4308, 2016.

87. Chang CC, Lin HH, Lin JK, Lin CC, Lan YT, Wang HS, Yang SH, Chen WS, Lin TC, Jiang JK and Chang SC: FBXW7 mutation analysis and its correlation with clinicopathological features and prognosis in colorectal cancer patients. Int J Biol Markers 30: e88-e95, 2015.

88. Tu K, Zheng X, Zan X, Han S, Yao Y and Liu Q: Evaluation of Fbxw7 expression and its correlation with the expression of c-Myc, cyclin E and p53 in human hepatocellular carcinoma. Hepatol Res 42: 904-910, 2012.

89. Enkhbold C, Utsunomiya T, Morine Y, Imura S, Ikemoto T, Arakawa Y, Kanamoto M, Iwahashi S, Saito Y, Ishikawa D and Shimada M: Loss of FBXW7 expression is associated with poor prognosis in intrahepatic cholangiocarcinoma. Hepatol Res 44: E346-E352, 2014.

90. Ishii N, Araki K, Yokobori T, Gantumur D, Yamanaka T, Altan B, Tsukagoshi M, Igarashi T, Watanabe A, Kubo N, et al: Reduced FBXW7 expression in pancreatic cancer correlates with poor prognosis and chemotherapeutic resistance via accumulation of MCL1. Oncotarget 8: 112636-112646, 2017.

This work is licensed under a Creative Commons Attribution-NonCommercial-NoDerivatives 4.0 International (CC BY-NC-ND 4.0) License. 